\title{
Pubertal pathways and the relationship to anthropometric changes in childhood: The Fels longitudinal study
}

\author{
Wen Wan, Xiaoyan Deng, Kellie J. Archer, Shumei S. Sun* \\ Department of Biostatistics, School of Medicine, Virginia Commonwealth University, Richmond, USA \\ Email: ${ }^{*}$ ssun@,vcu.edu
}

Received 21 February 2012; revised 21 April 2012; accepted 2 May 2012

\begin{abstract}
Objective: To examine the relationship of the initial manifestation of pubertal development in children to anthropometric measurements recorded during the early childhood and adolescence. Methods: The Fels Longitudinal study is an observational study of growth and development of healthy white children. A total of 109 boys and 75 girls with serial self-assessments of Tanner stages of genital/breast and pubic hair developments provided data for a longitudinal analysis with a linear mixed model. Results: About 11.0\% of boys and $22.7 \%$ of girls witnessed the appearance of pubic hair (adrenarche) prior to the onset of genital/breast growth (gonadarche/thelarche) and about $13.7 \%$ of boys and $22.7 \%$ of girls experienced the onset of gonadarche/thelarche prior to adrenarche. The remaining $75.3 \%$ of boys and $54.7 \%$ of girls were concordant for adrenarche and gonadarche/thelarche. During the first two years of life, boys and girls with earlier gonadarche and thelarche than adrenarche were found to have more rapid weight gain than those with earlier adrenarche than gonadarche/thelarche. During early childhood from age 2 - 7 years, those girls with early thelarche had higher body mass index (BMI) and waist circumference to height ratio (waist/ height) than those with early adrenarche. In children of ages 8 - 20, girls with early gonadarche had higher BMI z-scores than those with early adrenarche. Conclusion: Girls with early thelarche and later adrenarche, have more rapid mean weight gain during the first two years of life, higher BMI and waist/height during early childhood, and higher BMI z-scores during adolescence. Boys with early gonadarche and later adrenarche experienced more rapid weight gain during the first two years of life than boys with early adrenarche and later gonadarche. In other words, girls with early thelarche are more likely to be triggered by early accumulation of fat mass than those with early adrenarche.
\end{abstract}

${ }^{*}$ Corresponding author.
Keywords: Adrenarche; Gonadarche; Children Obesity; Body Mass Index (BMI); BMI z-Score

\section{INTRODUCTION}

Information on timing of pubertal maturation is important for understanding the etiology of pubertal disorders as well as normal development [1]. It is also important to document synchronous or asynchronous pubertal development, given that asynchrony may have implications for health problems [1,2]. Pubertal maturation consists of two associated processes: adrenarche, the reactivation of adrenal androgen production; and gonadarche, the reactivation of the hypothalamic-pituitary-gonadal axis [3]. Appearance of pubic hair is considered a physical manifestation of adrenarche in boys and girls and developments of genital/breast are considered a manifestation of gonadarche in boys/girls. At the beginning of pubertal development, a substantial minority experiences a disparity between genital/breast and pubic hair maturation.

Most investigations of pubertal development are crosssectional, involving different adolescents assessed at different ages. Such investigations are not designed to characterize childhood growth. Relatively fewer investigations are longitudinal and include measurements of anthropometric changes during infancy and childhood. There were increasing evidences [4-10] that the accumulation of a critical fat mass during childhood may be related to the reawakening of the secretory hypothalamus that initiates adrenarche, gonadarche/thelarche in boys/ girls. Lee et al. [5] found that higher body mass index (BMI) z-score in girls as young as three years of age and greater rate of change in BMI between three and six years old are associated with earlier onset of thelarche, suggesting that increasing rates of childhood obesity in the United States may result in an earlier average age of onset of breast development. Biro et al. [2] reported differences in anthropometric measurements between girls who had experienced asynchronous pubertal onset. They found that girls who experienced thelarche before adrenarche had greater sum of skinfold thicknesses, BMI, and 
percent body fat, one year before the onset of puberty and throughout the puberty, suggesting that girls with asynchronous puberty with early thelarche may be at increased risk for obesity later in life.

An unanswered question is whether adrenarche or gonadarche/thelarche in boys/girls is more likely to be triggered by early accumulation of fat mass. The age of the population studied by Biro et al. [2] ranged in age from 9 - 20 years and did not extend to include childhood before pubertal onset. In addition, the longitudinal analysis in Biro et al. [3] that examined the effect of time elapsed since the onset of puberty and the effect of asynchronous onset of puberty on anthropometric variables such as BMI may be confounded by age, i.e., as children grow during adolescence, their BMI values increase.

The present study tested the following hypotheses: 1) During the first two years of life, there are differences in weight gain in children with asynchronous puberty between those who experience adrenarche first and those who experience gonadarche/thelarche first; 2) During early childhood (ages 2 - 7) and before puberty, there are differences in BMI, waist circumference to height ratio (waist/height) in children with asynchronous puberty between those who experience adrenarche first and those who experience gonadarche/thelarche first; 3) During adolescence (ages 8 - 20), there are differences in BMI z-score in children with asynchronous puberty between those who experience adrenarche first and those who experience gonadarche/thelarche first.

\section{MATERIALS AND METHODS}

\subsection{Study Sample}

This analysis is based on serial data from a total of 184 white children (109 boys and 75 girls) in the Fels Longitudinal Study who had self-assessed Tanner stage data of pubic hair and genital/breast developments. The Fels Longitudinal Study is an observational study of growth and development of healthy children in southwest Ohio, from birth through adulthood [11]. All procedures of the Study were approved by the Institutional Review Boards of Wright State University and Virginia Commonwealth University, and all participants provided written consent to join the Fels Longitudinal Study.

\subsection{Study Measurements}

All study subjects were measured by anthropometric and laboratory techniques as described by Roche [11]. The participants were examined at birth, 1, 2, 3, 6, 9, and 12 months, then semi-annually to 18 years, and biennially thereafter. Childhood measurements include birth weight $(\mathrm{kg})$, weight $(\mathrm{kg})$, height (or length) $(\mathrm{cm})$, and waist circumference $(\mathrm{cm})$. Body weight was measured to $0.1 \mathrm{~kg}$ using a SECA scale. Height was measured to $0.1 \mathrm{~cm}$ using a Holtain stadiometer. These data were collected following the Anthropometric Standardization procedures [12]. Weight gain at a certain age during the first two years of life was calculated by subtracting birth weight from body weight measured at scheduled visits. BMI values were calculated as weight $/$ height $^{2}\left(\mathrm{~kg} / \mathrm{m}^{2}\right)$. Waist/ height was calculated as waist circumference $(\mathrm{cm}) /$ height (cm). Serial BMI z-scores for each individual were derived using the US CDC 2000 reference growth charts [13]. In accordance with CDC guidelines, a z-score below the $5^{\text {th }}$ percentile was considered underweight, a score between the $5^{\text {th }}$ and $85^{\text {th }}$ percentile was considered desirable, a score at or above the $85^{\text {th }}$ percentile but below the $95^{\text {th }}$ percentile was considered at risk for overweight, and a score at or above the $95^{\text {th }}$ percentile was considered overweight.

Self-assessments of Tanner stages of pubic hair development in boys and girls, genital development in boys, and breast development in girls were obtained every six months from ages 8 to 18 years by having each participant match his or her pubic hair/genital/breast development against a set of standardized photographs [14]. Each participant's serial data permitted the identification of inconsistent or implausible classifications. Adrenarche was defined by the first appearance of pubic hair, gonadarche by increase in testis size; and thelarche by areolar/breast development (i.e., the onset of Tanner stage 2 of puberty). Age at the onset of puberty was defined as the child's age at the first appearance of pubic hair or testis or breast development. In addition, girls and/or parents were asked at each visit whether menarche had occurred, and the girl's age in months was recorded.

\subsection{Statistical Analysis Methods}

Descriptive statistics were used to describe the study sample. One way analysis of variance (ANOVA) was used to compare age of onset of puberty between groups defined as adrenarche first vs gonadarche/thelarche first. Repeated measures analysis of variance through a linear mixed model was used to test the three hypotheses: whether there is an association between asynchronous puberty and anthropometric measurements in ages $0-2$, 2 - 7 and during puberty, respectively. In addition, a specific comparison of the two asynchronous-puberty groups at a single time point was conducted using a contrast test. Each statistical test was two-sided and designated to be significant at $\alpha=0.05$ level. All computations were performed using $\operatorname{SAS}^{\circledR} 9.2$ Software.

\section{RESULTS}

The numbers of male and female participants with serial BMI data are summarized in Table 1, along with de- 
scriptive statistics of BMI values measured at the beginning of the study by sex and puberty developmental group. Ages at the first appearance of Tanner stage 2 for pubic hair development in each sex, Tanner stage 2 testis development in boys, and Tanner stage 2 breast development in girls are summarized respectively, in Table 2. Tanner stage 2 pubic hair development was reached at a mean (SD) age of 10.89 (1.06) years (range 8.39 - 14.02) in boys and $10.56(0.92)$ years (range $8.08-13.03)$ in girls. Tanner stage 2 testis development was reached at a mean (SD) age of 10.80 (1.07) years (range 8.39 - 13.51), and Tanner stage 2 breast development was reached at a mean (SD) age of 10.51 (1.05) years (range 8.08 - 13.11). Six boys were outliers with appearance of Tanner stage 2 testis before they were 9 years old; five of the six had also reached Tanner stage 2 pubic hair before they were 9 years old. None of the girls had any evidence of the premature onset of puberty.

Table 1. Summary of numbers of childhood serial examinations of BMI by ages $0-2,2-7$, and years -2 to 10 since puberty and by sex and descriptive statistics of BMI values measured at the beginning of the study by sex and puberty developmental group.

\begin{tabular}{|c|c|c|c|c|}
\hline \multicolumn{2}{|c|}{ Number of serial examinations of BMI } & Number of boys & Number of girls & Total number of subjects \\
\hline \multicolumn{5}{|c|}{ Ages in $0-2$ years } \\
\hline \multicolumn{2}{|l|}{$1-4$} & 61 & 42 & 103 \\
\hline \multicolumn{2}{|l|}{$5-8$} & 38 & 29 & 67 \\
\hline \multicolumn{2}{|l|}{ Total } & 99 & 71 & 170 \\
\hline \multicolumn{5}{|c|}{ Ages in $2-7$ years } \\
\hline \multicolumn{2}{|l|}{$1-4$} & 37 & 30 & 67 \\
\hline \multicolumn{2}{|l|}{$5-8$} & 21 & 12 & 33 \\
\hline \multicolumn{2}{|l|}{$9-12$} & 33 & 25 & 58 \\
\hline \multicolumn{2}{|l|}{ Total } & 91 & 67 & 158 \\
\hline \multicolumn{5}{|c|}{ Years in $-2-10$ since puberty } \\
\hline \multicolumn{2}{|l|}{$1-8$} & 3 & 3 & 6 \\
\hline \multicolumn{2}{|l|}{$9-16$} & 8 & 11 & 19 \\
\hline \multicolumn{2}{|l|}{$16-23$} & 16 & 20 & 36 \\
\hline \multicolumn{2}{|l|}{ Total } & 27 & 34 & 61 \\
\hline \multicolumn{5}{|c|}{ BMI at Birth in Boys } \\
\hline \multicolumn{2}{|c|}{ Overall } & Adrenarche-first & Concordance & Gonadarche-first \\
\hline $\mathrm{N}$ & 86 & 9 & 68 & 9 \\
\hline Mean & 12.9 & 13.0 & 12.8 & 12.8 \\
\hline Std Dev & 1.6 & 1.6 & 1.7 & 0.4 \\
\hline Min & 6.0 & 11.4 & 6.0 & 12.2 \\
\hline $\operatorname{Max}$ & 16.3 & 15.8 & 16.3 & 13.5 \\
\hline \multicolumn{5}{|c|}{ BMI at Birth in Girls } \\
\hline $\mathrm{N}$ & 59 & 14 & 31 & 14 \\
\hline Mean & 13.1 & 13.4 & 13.1 & 12.6 \\
\hline Std Dev & 1.6 & 2.3 & 1.3 & 1.6 \\
\hline Min & 9.5 & 11.2 & 10.7 & 9.5 \\
\hline $\operatorname{Max}$ & 17.9 & 17.9 & 15.6 & 14.9 \\
\hline
\end{tabular}


Table 2 also shows that the mean (SD) ages of menarche were 12.81 (1.14) years in all girls who had records of ages of menarche, 12.99 (1.03) years in those girls with asynchronous puberty with adrenarche onset prior to thelarche, $12.70(1.13)$ years in those girls with thelarche onset prior to adrenarche, and 12.78 (1.22) years in girls with concordant puberty. None of these differences in age of menarche were significant. However, among girls with asynchronous puberty, those with early thelarche reached the Tanner stage 2 seven months earlier than those with early adrenarche ( $p$-value $=0.016$ ). No significant difference was found in asynchronous boys in the age of onset of gonadarche or adrenarche. Eleven percent of the boys and $22.7 \%$ of the girls experienced earlier appearance of pubic hair than testis/ breast development and $13.7 \%$ of the boys and $22.7 \%$ of the girls experienced earlier onset of testis or breast de- velopment than pubic hair. The remaining $75.3 \%$ of the boys and $54.7 \%$ of the girls experienced concordant puberty development.

\subsection{Results in Weight Gain from Birth to 2 Years}

Figure 1 shows the results of our longitudinal analysis comparing the two kinds of asynchronous puberty in terms of weight gain during the first two years of life. Boys who experienced early gonadarche had more rapid weight gain during the first two years of life than those who experienced early adrenarche (overall $p$-value $=$ 0.006). Asynchronous boys with early gonadarche gained significantly more weight by 6 months than boys with early adrenarche $(4.0 \mathrm{~kg}$ vs $2.1 \mathrm{~kg}$, p-value $=0.015)$. Girls with asynchronous puberty with early thelarche gained more weight during the first two years of life than

Table 2. Summary of onsets of testis/breast, pubic hair developments and onset of menarche by sex and puberty developmental group.

\begin{tabular}{|c|c|c|c|c|c|c|c|c|c|c|c|c|c|}
\hline & & \multicolumn{3}{|c|}{ Overall } & \multicolumn{3}{|c|}{ Adrenarche-first } & \multicolumn{3}{|c|}{ Concordance } & \multicolumn{3}{|c|}{ Gonadarche-first } \\
\hline & & $\begin{array}{c}\text { Testis } 2 \\
\text { (Breast 2) }\end{array}$ & $\begin{array}{l}\text { Pubic } \\
\text { Hair } 2\end{array}$ & Menarche & $\begin{array}{c}\text { Testis } 2 \\
\text { (Breast 2) }\end{array}$ & $\begin{array}{l}\text { Pubic } \\
\text { Hair } 2\end{array}$ & Menarche & $\begin{array}{c}\text { Testis } 2 \\
\text { (Breast 2) }\end{array}$ & $\begin{array}{l}\text { Pubic } \\
\text { Hair } 2\end{array}$ & Menarche & $\begin{array}{c}\text { Testis } 2 \\
\text { (Breast 2) }\end{array}$ & $\begin{array}{l}\text { Pubic } \\
\text { Hair } 2\end{array}$ & Menarche \\
\hline \multirow[t]{5}{*}{ Boys } & $\mathrm{N}$ & 109 & 109 & & 12 & 12 & & 82 & 82 & & 15 & 15 & \\
\hline & Mean & 10.8 & 10.89 & & 11.25 & 10.47 & & 10.82 & 10.82 & & 10.33 & 11.59 & \\
\hline & Std Dev & 1.07 & 1.06 & & 0.71 & 0.56 & & 1.08 & 1.08 & & 1.14 & 1.02 & \\
\hline & Min & 8.39 & 8.39 & & 10.49 & 9.83 & & 8.39 & 8.39 & & 8.72 & 10.43 & \\
\hline & Max & 13.51 & 14.02 & & 12.59 & 11.48 & & 13.03 & 13.03 & & 13.51 & 14.02 & \\
\hline \multirow[t]{5}{*}{ Girls } & $\mathrm{N}$ & 75 & 75 & 59 & 17 & 17 & 14 & 41 & 41 & 29 & 17 & 17 & 16 \\
\hline & Mean & 10.51 & 10.56 & 12.81 & 11.29 & 10.42 & 12.99 & 10.49 & 10.49 & 12.78 & 9.79 & 10.89 & 12.70 \\
\hline & Std Dev & 1.05 & 0.92 & 1.14 & 0.77 & 0.6 & 1.03 & 1.02 & 1.02 & 1.22 & 0.84 & 0.91 & 1.13 \\
\hline & Min & 8.08 & 8.08 & 9.80 & 9.88 & 9.37 & 11.38 & 8.08 & 8.08 & 10.31 & 8.54 & 9.49 & 9.80 \\
\hline & Max & 13.11 & 13.03 & 14.93 & 13.11 & 11.47 & 14.54 & 12.88 & 12.88 & 14.66 & 11.07 & 13.03 & 14.93 \\
\hline
\end{tabular}

"Testis 2 " in boys, "breast 2" in girls, and "pubic hair 2" refer to age at the first Tanner genital, breast, and pubic hair stage 2, respectively.
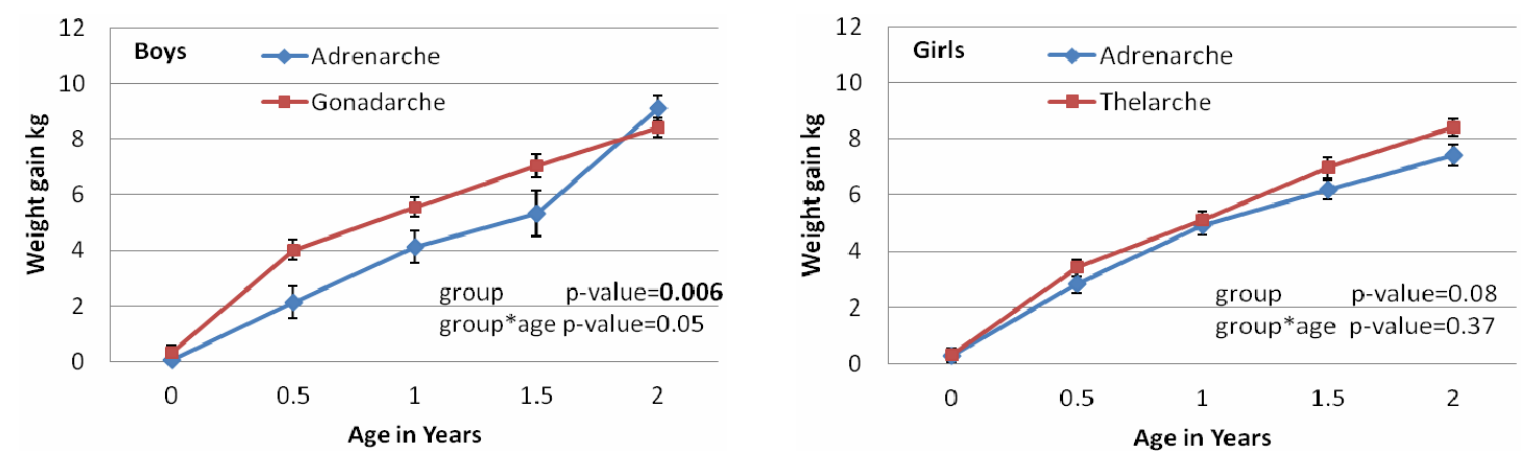

Figure 1. Plots of least squares means and standard errors of weight gain from birth in a linear mixed model vs ages from birth to 2 years by pathway and by gender, with p-values for comparing the two pathways and for its interaction with age. 
those with early adrenarche (overall p-value $=0.08$ ). Asynchronous girls with early thelarche gained significantly higher mean weight by 2 years than girls with early adrenarche $(8.4 \mathrm{~kg}$ vs $7.4 \mathrm{~kg}$, p-value $=0.047)$. Our results indicate that children with asynchronous puberty with early thelarche/gonadarche were likely to gain more weight than those with early adrenarche early in childhood.

\subsection{Results in BMI and Waist/Height Ratio from 2 - 7 Years}

Figure 2 shows the results of the longitudinal analysis of BMI during early childhood from ages 2 through 7 years in boys and girls with asynchronous puberty. Both asynchronous boys and girls had linear or quadratic patterns of BMI by age. Asynchronous children with early gonadarche or thelarche had consistently greater BMI than those with early adrenarche, but the difference between the two types of asynchronous puberty was significant only among the girls (overall p-value $=0.002$ ). The BMI means from ages 2 through 7 in the gonadarche-first boys fell in the range of 16.2 - 17.3, while the BMI means in the adrenarche-first boys were in the range of 15.2 - 16.2. The BMI means in the thelarche-first girls were in the range of 16.9 - 18.6, while the BMI means in

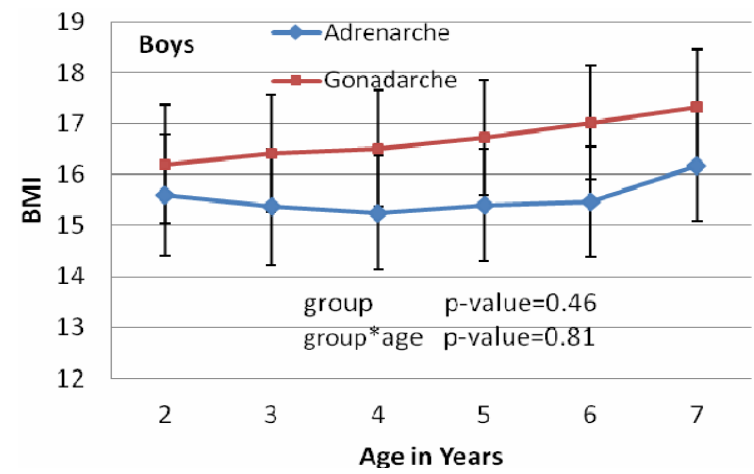

the adrenarche-first girls were in the range of 14.6 - 15.4 . BMI means in the thelarche-first girls were about 2.5 $\mathrm{kg} / \mathrm{m}^{2}$ greater than in the adrenarche-first girls and the differences increase with age. The mean BMI values in girls with the two types of asynchronous puberty differed significantly at age from 2 through 7 years, and the p-values range from $0.0003-0.02$. In addition, the thelarche-first girls had their adiposity rebound at a mean age of two years or younger; much earlier than adrenarche-first girls whose adiposity rebound took place at a mean age of four years. These results suggest that girls with early thelarche had greater BMI values than those with early adrenarche during childhood.

Figure 3 depicts waist/height during ages 2 - 7 years of boys and girls with asynchronous puberty. Both boys and girls had decreasing waist/height with increasing age. There was no significant difference in waist/height between boys with the two types of asynchronous puberty. However, girls with thelarche-first puberty had consistently greater waist/height than girls with adrenarchefirst puberty from ages 2 - 7 years (overall p-value = 0.0006). The differences between the two types of asynchronous puberty in girls were significant at each age, from 2 to 7 years, and the corresponding p-values were in the range of $0.001-0.02$.

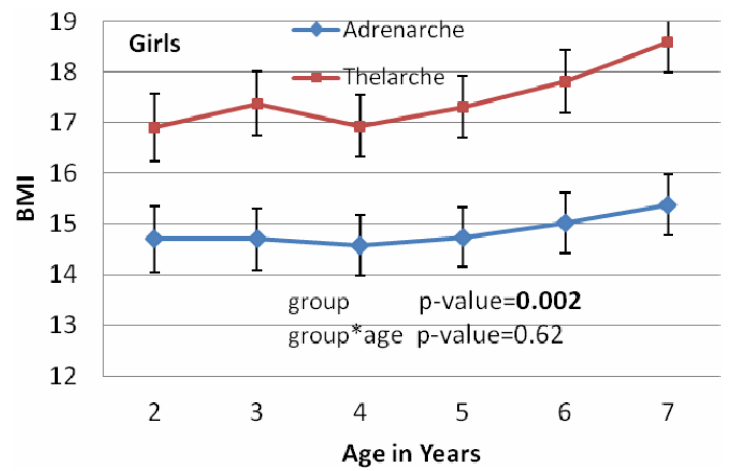

Figure 2. Plots of least squares means and standard errors of waist/height in a linear mixed model vs ages in 2 - 7 years by gender and by asynchronous group and with p-values for comparing the two groups and for its interaction with age.
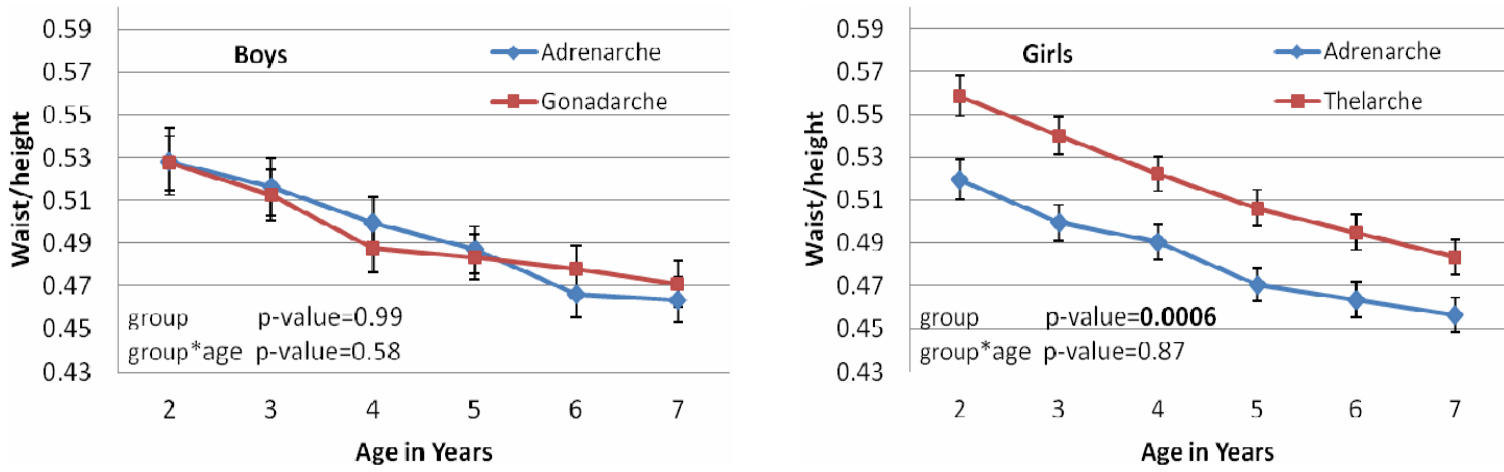

Figure 3. Plots of least squares means and standard errors of waist/height in a linear mixed model vs ages from 2 - 7 years by gender and by asynchronous group, with p-values for comparing the two groups and for its interaction with age. 


\subsection{Results in BMI z-Score from Onset of Puberty}

To longitudinally examine children with asynchronous puberty with respect to the effect of time since the onset of puberty on adiposity in adolescence, we used BMI Z-score adjusted for age to compare the two types of pubertal onset (Figure 4). Boys with either type of pubertal onset showed no significant difference in BMI z-scores during the years since pubertal onset, where mean BMI $\mathrm{z}$-scores were about -0.4 to -0.2 . However, girls with asynchronous puberty with thelarche-first had significantly greater mean BMI z-scores than those with adrenarche-first during the years since the onset of puberty (overall $p$-value $=0.02$ ). The thelarche-first girls had relatively stable mean BMI z-scores around +0.4 across the years -2 to +10 since onset of puberty, while the adrenarche-first girls had significantly lower and less stable mean BMI $\mathrm{z}$-scores during the years from -2 to +10 since the onset of puberty, where mean BMI $\mathrm{z}$-scores were -0.6 to -0.8 before and at onset of puberty, then increased to around -0.1 after onset of puberty. All the mean BMI z-scores from each pubertal group in both boys and girls fell between the $5^{\text {th }}$ and $85^{\text {th }}$ percentile and each group was considered desirable weight on average. The change of BMI z-scores over time makes the interaction effect between types of asynchronous puberty and year significant ( $\mathrm{p}$-value $=0.003$ ). In addition, the differences between the two types of asynchronous puberty at each year from -2 through +2 since the onset of puberty were significant at $p$-values $<0.05$. Figure 4 also shows that as girls' age, the difference between the influences of the two types of asynchronous puberty tended to get smaller. The results show that during adolescence girls with thelarche-first asynchronous puberty are more likely to have higher BMI z-scores than those with adrenarche.

\section{DISCUSSION}

To our knowledge, our study is the first to reveal the

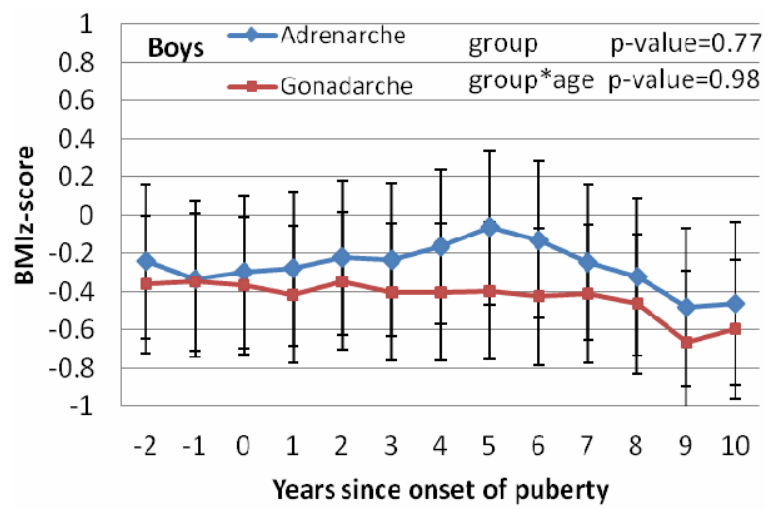

influences of early childhood growth on the onset of puberty in boys and girls with synchronous and asynchronous puberty.

Despite many years of investigation in human and animal models, it remains largely unknown how to coax the hypothalamic pulse generator to initiate adrenarche and gonadarche in boys and girls. However, there is increasing evidence $[4-10,15]$ that the attainment of a critical fat mass during childhood may trigger the reawakening of the secretory hypothalamus. In addition, Alwis et al. [16] reported that by dual energy X-ray absorptionmetry (DEXA), bone size, bone mass, lean mass, and fat mass increased constantly from age 6 until the rapid increase in all traits at puberty in both boys and girls. Specifically, based on the DEXA data provided in Alwis et al. [16], total body lean mass increased by $21.2 \%$ (boys) and $18.4 \%$ (girls) from about ages 6 to 8 , while total body fat mass increased by $34.5 \%$ (boys) and $28.6 \%$ (girls). The growth rates in fat mass are at least $10 \%$ higher than in lean mass in both boys and girls, during the mid-growth spurt around the age of $7[17,18]$. An unanswered question is whether adrenarche or gonadarche in boys and/or girls is more likely to be triggered by early accumulation fat mass.

Adrenarche and gonadarche are two separate pubertal maturational events, although they are associated with each other. Adrenarche is characterized by the reactivation of adrenal androgen production and by impressive increases in dehydroepiandrosterone (DHEA) and its sulfate (DHEAS), both products of the zona reticularis of the adrenal gland. However, gonadarche is characterized by the earliest gonadal changes by reactivation of the hypothalamic-pituitary-gonadal axis. The increase in adrenal androgens is not associated with an increase in sensitivity of gonadotropins to GnRH or with sleep-associated LH secretion characteristic of puberty [15]. During normal growth, adrenarche and gonadarche are temporally closely linked, but in pathological situations, adrenarche can occur without subsequent gonadarche

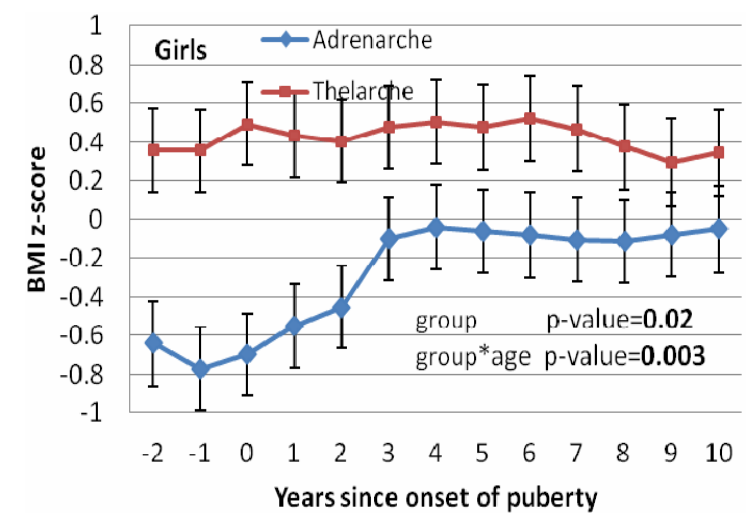

Figure 4. Plots of least squares means and standard errors of BMI z-score in a linear mixed model vs years since puberty by gender and by asynchronous group, with p-values for comparing the two groups and for its interaction with age. 
and gonadarche without preceding adrenarche $[9,19]$.

In addition, adrenarche is considered to be implicated in the timing of puberty. Biro et al. [3] reported that the development of pubic hair in girls, preceding their breast development, may represent true pubertal maturation, given similar age and height velocities at onset of secondary sexual characteristics.

The validity of self-assessment of Tanner stages has been studied by several groups [20-23]. Taylor et al. [20] reported that self-assessment of pubic hair distribution by boys and girls agreed with physicians' assessments to within one Tanner stage $88 \%$ of the time. Schmitz et al. [21] validated self-assessments of pubertal stage against physicians' ratings and reported agreement within one Tanner stage in more than $85 \%$ of assessments. Norris and Richter [22] reported significant concordance between adolescents' and same sex health professionals' assessment of pubic hair in females ( $\kappa$ coefficients 0.71 ) and in males ( $\kappa$ coefficients 0.63 ). Leone and Comtois [23] reported that self-assessment of sexual maturity is a valid and reliable method, compared with physician ratings ( $\kappa$ coefficients of 0.79 for pubic hair and 0.67 for genital development for boys and 0.75 and 0.85 for pubic hair and breast development for girls, respectively).

This study analyzed the Fels longitudinal data from 109 boys and 75 girls who had self-assessed Tanner stage data of genital/breast and pubic hair developments. We found that the mean ages at onset of appearance of pubic hair were 10.9 in boys and 10.6 in girls and the mean ages at onset of development of testis/breast were 10.8 in boys and 10.5 in girls. These results are similar to those reported by Remer et al. [9] in children of the Dortmund Nutritional and Anthropometric Longitudinally Designed study in Germany (where the Tanner stages were designated by physicians): the mean ages of adrenarche were 11.6 in boys and 10.9 in girls, and the mean ages of gonadarche were 10.9 in boys and of thelarche 10.6 in girls.

We observed asynchronous maturation in the initial manifestation of puberty in $25 \%$ of the boys and $45 \%$ of the girls. About one-half of these asynchronous children experienced early appearance of pubic hair and one-half of them experienced early onset of testis/breast development. The remaining $75 \%$ of the boys and $55 \%$ of the girls experienced a synchronous onset of puberty with concordance of adrenarche, thelarche, and gonadarche. These results agree with those of Schubert et al. [24], using the data from the third National Health and Nutrition Examination Survey (NHANES III, 1988-1994) (in which Tanner stages were designated by physicians): about $20 \%$ of the white boys and $19 \%$ of the white girls experienced early adrenarche and, about $8 \%$ of the boys and $14 \%$ of the girls experienced early thelarche. These authors found that $69 \%$ of the boys and $66 \%$ of the girls experienced a synchronous onset of puberty. Our results are also similar to those of Taranger et al. [25] with reported synchronous breast and pubic hair development in about $47 \%$ of the girls in the study.

In our study, among boys and girls with asynchronous puberty, we found differences between children with early adrenarche and children with early thelarche, and gonadarche in anthropometric changes during the first two years of life, during early childhood before the onset of puberty, and during adolescence. During the first two years of life, asynchronous boys and girls with early gonadarche/thelarche experienced more rapid weight gain than those with early adrenarche. During early childhood, before the onset of puberty, asynchronous girls with early thelarche had significantly greater BMI and waist/height than those with early adrenarche. In addition, during adolescence, from two years before puberty onset to ten years after, asynchronous girls with early thelarche had significantly greater BMI z-scores than those with early adrenarche, especially, during the period from two years before to two years after the onset of puberty. As girls grow during adolescence, the difference in influence of the two types of asynchronous puberty wanes and becomes non-significant by $8-10$ years. We did a longitudinal analysis similar to that of Biro et al. [2] during adolescence, and our findings were similar to theirs. Asynchronous girls had profoundly different anthropometric changes from the boys according to type of pubertal onset. This striking sexual dimorphism highlights the power of gondal hormones to affect body composition and to counter-balance the effect of adrenal androgens.

In addition, we found that the girls with thelarche-first asynchronous puberty earlier than those with adrenarchefirst $(9.8 \pm 0.8$ vs $10.4 \pm 0.6)$. Biro et al. [2] found no difference $(10.7 \pm 0.7$ vs $10.7 \pm 0.9)$, perhaps because their study population was already 9 or 10 years of age at entry. The mean age of menarche in those girls with thelarche-first asynchronous puberty was about 4 months earlier than in girls with the adrenarche-first puberty, similar to the results of Biro et al. [2], but our statistical testing is not significant, while their testing was.

\subsection{Implications}

Overweight during childhood and early timing of puberty have both been linked to health and psychological problems in adults [10]. Overweight and obesity increase the risk of cardiovascular disease, diabetes, and cancer and psychosocial outcomes such as depression and low selfesteem $[10,26]$. Our finding that overweight during early childhood in girls may trigger earlier onset of breast development, suggesting that being overweight during early childhood may also place girls at increased risk for adverse outcomes associated with early thelarche such as psychiatric disorders and deficits in psychosocial func- 
tioning $[5,10,27,28]$, earlier initiation of alcohol use, sexual intercourse and teenage pregnancy [5,29], of greater risk of reproductive cancer $[2,10,30]$, and a greater likelihood of adult obesity [3,5,10,31].

\subsection{Limitations}

This study had several limitations. Fat mass was assessed with BMI, waist/height, or BMI z-score, which are a surrogate measure of adiposity, and do not account for differences in body fat distribution. If there had been more subjects, we might have seen significant differences in anthropometric changes in boys between the two asynchronous pubertal developments, especially during early childhood (in ages 2 - 7). Also if more subjects were available, significant differences in BMI z-score in girls between the two asynchronous pathways might be seen not only during the period from two years before to two years after the onset of puberty, but also by $8-10$ years. The results of the age when boys and girls reach Tanner 2 may be biased due to the possible cohort effects from the long-period Fels Study that started since 1929. The study relied on self-assessment to determine the Tanner stage, which may not be an accurate assessment, especially to determine genital development in boys and breast development in girls. The true genital/breast developments refer to activation of hypothalamic-pituiatary-gonadal axis. Premature thelarche and lipomastia may give a false impression of the true breast developpment. It is also not easy to self-assess the testicular volume of at least $4 \mathrm{~mL}$, indicating onset of gonadarche in boys, which may need to be assessed by an experienced Pediatric Endocrinologist with the use of an orchidometer. Finally, we only evaluated Tanner pubic hair/testis/breast stage 2, but not the other stages 3-5. Some who have similar timing of puberty may have different speeds to reach Tanner stage 5 [1]. In future studies we plan to discover if those who reach Tanner stage 5 faster are more likely associated with obesity.

\section{CONCLUSION}

In summary, we have found in a longitudinal analysis of body composition and puberty in white boys and girls that 1) The majority of boys and girls experienced the synchronous appearance of pubic hair and testis or breast maturation ( $75 \%$ in boys and 55\% in girls); 2) Boys with early gonadarche and girls with early thelarche were likely to gain more rapid weight during the first two years of life than boys and girls with early adrenarche; 3 ) Girls with early thelarche had have higher BMI and waist/height during early childhood than those with early adrenarche; 4) Girls with early thelarche were likely to have higher BMI z-score during adolescence than those with early adrenarche. In other words, girls with early thelarche are more likely to be triggered by early accumulation of fat mass than those with early adrenarche.

\section{ACKNOWLEDGEMENTS}

We thank the reviewers for their helpful and useful comments. This study was supported by National Institutes of Health grants: U01HL101064, R01HD060913, R01HD038356, R01HD038356S, DK 071485, DK 071485S, HL 072838 and HD 12252.

\section{REFERENCES}

[1] Susman, E.J., Houts, R.M., Steinberg, L., et al. (2010) Longitudinal development of secondary sexual characteristics in girls and boys between ages 9.5 and 15.5 years. Archives of Pediatric and Adolescent Medicine, 164, 166173. doi:10.1001/archpediatrics.2009.261

[2] Biro, F.M., Lucky, A.W., Simbartl, L.A., et al. (2003) Pubertal maturation in girls and the relationship to anthropometric changes: Pathways through puberty. Journal of Pediatrics, 142, 643-646. doi: $10.1067 / \mathrm{mpd} .2003 .244$

[3] Biro, F.M., Huang, B., Daniels, S.R. and Lucky, A.W. (2008) Pubarche as well as thelarche may be a marker for the onset of puberty. Journal of Pediatric and Adolescent Gynecology, 21, 323-328. doi:10.1016/j.jpag.2007.09.008

[4] Frisch, R. and Revelle, R. (1970) Height and weight at menarche a hypothesis of critical body weights and adolescent events. Science, 169, 397-399. doi:10.1126/science.169.3943.397

[5] Lee, J.M., Appugliese, D., Kaciroti, N., Corwyn, R.F., Bradley, R.H. and Lumeng, J.C. (2007) Weight status in young girls and the onset of puberty. Pediatrics, 119, 624-630. doi:10.1542/peds.2006-2188

[6] Dunger, D.B., Ahmed, M.L. and Ong, K.K. (2006) Early and late weight gain and the timing of puberty. Molecular and Cellular Endocrinology, 140-145, 254-255. doi:10.1016/j.mce.2006.04.003

[7] Mills, J.L., Shiono, P.H., Shapiro, L.R., et al. (1986) Early growth predicts timing of puberty in boys: Results of a 14-year nutrition and growth study. Journal of Pediatrics, 109, 543-547. doi:10.1016/S0022-3476(86)80141-X

[8] Shi, L.J., Wudy, S.A., Buyken, A.E., et al. (2009) Body fat and animal protein intakes are associated with adrenal androgen secretion in children. American Joural of Clinical Nutrition, 90, 1321-1328. doi:10.3945/ajen.2009.27964

[9] Remer, T., Shi, L.J., Buyken, A.E., Maser-Gluth, C., Hartmann, M.F. and Wudy, S.A. (2010) Prepubertal adrenarchal androgens and animal protein intake independently and differentially influence pubertal timing. Journal of Clinical Endocrinology and Metabolism, 95, 3002-3009. doi:10.1210/jc.2009-2583

[10] Davison, K.K., Susman, E.J. and Birch, L.L. (2003) Percent body fat at age 5 predicts earlier pubertal development among girls at age 9. Pediatrics, 111, 815 . doi:10.1542/peds.111.4.815 
[11] Roche, A.F. (1992) Growth, maturation and body composition: The Fels Longitudinal Study 1929-1991. Cambridge University Press, Cambridge. doi:10.1017/CBO9780511661655

[12] Lohman, G.T., Roche, A.F. and Martorell, R. (1988) Anthropometric standardization reference manual. Human Kinetics, Champaign.

[13] Kuczmarski, R.J., Ogden, C.L., Grummer-Strawn, L.M., Flegal, K.M., Guo, S.S., Wei, R., Mei, Z., Curtin, L.R., Roche, A.F. and Johnson, C.L. (2000) CDC growth charts: United States. National Center for Health Statistics, Hyattsville.

[14] Roche, A.F. and Sun, S. (2003) Human growth: Assessment and interpretation. Cambridge University Press, Cambridge. doi:10.1017/CBO9780511525681

[15] Ibanez, L., Dimartino-Nardi, J., Potau, N., et al. (2000) Premature adrenarche-Normal variant or forerunner of adult disease? Endocrine Review, 21, 671-696. doi:10.1210/er.21.6.671

[16] Alwis, G., Rosengren, B., Stenevi-Lundgren, S., Düppe, H., Sernbo, I. and Karlsson, M.K. (2000) Normative dual energy X-ray absorptiometry data in Swedish children and adolescents. Acta Pediatrica, 99, 1091-1099. doi:10.1111/j.1651-2227.2010.01713.x

[17] Remer, T. and Manz, F. (2001) The midgrowth spurt in healthy children is not caused by adrenarche. The Journal of Clinical Endocrinology \& Metabolism, 86, 4183-4186. doi:10.1210/jc.86.9.4183

[18] Molinari, L., Largo, R.H. and Prader, A. (1980) Analysis of the growth spurt at age seven (mid-growth spurt). Helvetica Paediatrica Acta, 35, 325-334.

[19] Cutler, G.B. Jr. and Loriaux, D.L. (1980) Adrenarche and its relationship to the onset of puberty. Federation Proceedings, 39, 2384-2390.

[20] Taylor, J., Whincup, P., Hindmarsh, P., et al. (2001) Performance of a new pubertal self-assessment questionairre: A preliminary study. Paediatric and Perinatal Epidemiology, 15, 88-94. doi:10.1046/j.1365-3016.2001.00317.x

[21] Schmitz, K., Hovell, M., Nichols, J., et al. (2004) A validation study of early adolescents' pubertal self-assessments. Journal of Early Adolescence, 24, 357-384. doi:10.1177/0272431604268531
[22] Norris, S. and Richter, L. (2005) Usefulness and reliability of tanner pubertal self-rating to urban black adolescents in South Africa. Journal of Research on Adolescence, 15, 609-624. doi:10.1111/j.1532-7795.2005.00113.x

[23] Leone, M. and Comtois, A.S. (2007) Validity and reliability of self-assessment of sexual maturity in elite adolescent athletes. Journal of Sports Medicine and Physical Fitness, 47, 61-65.

[24] Schubert, C.M., Chumlea, W.C., Kulin, H.E., Lee, P.A., Himes, J.H. and Sun, S.S. (2005) Concordant and discordant sexual maturation among US children in relation to body weight and BMI. Journal of Adolescent Health, 37, 356-362. doi:10.1016/j.jadohealth.2005.03.009

[25] Taranger, J., Engstrom, I., Lichtenstein, H. and Svennberg-Redegren, I. (1976) Somatic pubertal development. Acta Paediatrica Scandinavica Journal, 258S, 121-135. doi:10.1111/j.1651-2227.1976.tb14766.x

[26] Dietz, W.H. (1998) Health consequences of obesity in youth: childhood predictors of adult disease. Pediatrics, 101, 518-525.

[27] Magnusson, D., Stattin, H. and Allen, V. (1985) Biological maturation and social development: A longitudinal study of some adjustment processes from mid-adolescence to adulthood. Journal of Youth and Adolescence, 14, 267-283. doi:10.1007/BF02089234

[28] Wilson, D.M., Killen, J.D., Hayward, C., et al. (1994) Timing and rate of sexual maturation and the onset of cigarette and alcohol use among teenage girls. Archives of Pediatric and Adolescent Medicine, 148,789-795. doi:10.1001/archpedi.1994.02170080019004

[29] Deardorff, J., Gonzales, N.A., Christopher, F.S., Roosa, M.W. and Millsap, R.E. (2005) Early puberty and adolescent pregnancy: The influence of alcohol use. Pediatrics, 116, 1451-1456. doi:10.1542/peds.2005-0542

[30] Stoll, B.A. (1998) Western diet, early puberty, and breast cancer risk. Breast Cancer Research Treatment, 49, 187 193. doi:10.1023/A:1006003110909

[31] Garn, S.M., La Velle, M., Rosenberg, K.R. and Hawthorne, V.M. (1986) Maturational timing as a factor in female fatness and obesity. American Journal of Clinical Nutrition, 43, 879-883. 